\title{
JEAN-LUC NANCY*
}

d'un côté, de l'autre, dedans, dehors, de un lado, del otro, adentro, afuera,

ici et lá

avant et après,

haut et bas,

animal et dieu,

femme et homme,

droite et gauche,

jamais, toujours,

ici, de l'autre,

dehors, femme,

avant, jamais,

animal, droite,

toujours amour,

dieu, lieu,

milieu,

homme, pomme, après, tout près, encore plus près. aquí y allí,

antes y después, arriba y abajo, animal y dios, mujer y hombre, derecha e izquierda, jamás, siempre, aquí, del otro, afuera, mujer, antes, jamás, animal, derecha, siempre amor, dios, lugar, mitad, hombre, manzana, después, muy cerca aún más cerca.

\footnotetext{
* Filósofo francés.
} 


\section{d'un}

d'un côté il y a le partage de l'espace, la fissuration cellulaire et le dechirement de vulve,

l'ecartelement de la droite à la gauche et du haut en bas, de l'avant en

arrière, la distance insurmontable,

l'impénétrabilité, les ponts qui par nature sont prets à

s'effondrer, les objets dont l'oeil ne fait pas le tour, le dur dehors, le dedans absent, restent les peaux et les pas, toutes et tous si minces, si fragiles, labiles, débiles, sans trève menacés de lames ou d'entraves, l'ouvert comme une breche, une faille, une défaillance

d'un côté

il y a quelque chose qui s'etend, et son extension

1'épuise,

d'un côté il y a l'autre

exposé.

\section{côté}

de l'autre côté il y a le partage de l'espace, la mêlée des gametes, l'intrication des acides hélicoidaux, le gonflement du ventre, l'occupation des lieux, le parcours des mains, des yeux, le repérage, l'ajointement des dimensions et des distances, l'horizon apaisant, les portes et fenêtres, les allées, les avenues, les autoroutes a voies nombreuses, les lieux divins, les espaces publics, l'ouvert comme une paume, comme une source, comme une bouche ouverte sur un chant, de l'autre côté il y a quelque chose qui s'étend, et son extension la repose, de l'autre côté il y a l'un exposé. 


\section{de un}

de un lado hay la partición del espacio, la fisura

celular y el desgarro de la vulva, la división de

derecha a izquierda y de arriba a abajo, de delante

hacia atrás, la distancia insuperable,

la impenetrabilidad, los puentes que por naturaleza están

listos a colapsar, los objetos

que el ojo no rodea,

el duro afuera, el adentro ausente, siguen siendo las pieles y los pasos, cada uno y todos tan finos, tan frágiles, lábiles, débiles, sin tregua amenazados

por hojas o por grilletes el abierto como una brecha, una apertura fina, una insuficiencia

de un lado

hay alguna cosa que se extiende, y su extensión

la agota,

de un lado hay el otro

expuesto.

\section{lado}

del otro lado hay la partición

del espacio, la mezcla de

los gametos, la complejidad de los ácidos helicoidales, la distensión del vientre, la ocupación de los lugares, el recorrido de las manos, de los ojos, la localización, la contigüidad de las dimensiones y de las distancias, el horizonte apaciguante, las puertas y las ventanas, las idas, las avenidas,

las autopistas de carriles numerosos, los lugares divinos, los espacios públicos, lo abierto como una palma, como una fuente, como una boca abierta hacia un canto

del otro lado hay alguna cosa que se extiende y su extensión la relaja, del otro lado hay el uno, expuesto. 